James Elkins *

\title{
A incursão da linguagem administrativa na educação dos artistas
}

James Elkins é PhD em História da Arte pela Universidade de Chicago (1989) e um dos mais importantes historiadores e críticos de Arte dos EUA. Ensina no Departamento de História da Arte, Teoria e Crítica, na Escola de Arte do Instituto de Chicago. Seu trabalho foca na história e na teoria em arte e imagens não artísticas, ciências e natureza. Seus livros recentes incluem "What Photography Is?"; "Art Critiques: A Guide" e "What Heaven Looks Like". <www.jameselkins.com> ORCID: 0000-0001-6041-5249

Larissa Siqueira Campos (tradução) Rafael Toledo (revisão)
Resumo Este ensaio reflete sobre o domínio da burocratização das avaliações universitárias na linguagem usada nas aulas de Arte.

Palavras chave Educação, Arte, Linguagem Administrativa, Avaliação Universitária.

\section{The incursion of administrative language into the education of artists}

Abstract This essay reflects on the domain of the bureaucratization of university evaluations in the language used in art classes.

Keywords Education, Art, Administrative Language, University Evaluation.

La incursión del lenguaje administrativo en la educación de los artistas

Resumen Este ensayo reflexiona sobre el dominio de la burocratización de las evaluaciones universitarias en el lenguaje utilizado en las clases de arte.

Palabras clave Educación, Arte, Lenguaje Administrativo, Evaluación Universitaria. 
A maneira como os artistas foram educados nos últimos trinta anos é muito diferente da maneira como eles foram educados em qualquer século anterior e em qualquer outra cultura.

Seria apropriado que a nova forma de educação ecoasse as mudanças culturais e artísticas nas últimas três décadas, caso tivesse a ver com política, gênero, globalização e pós-modernismo - e, em pequeno grau tem. Mas, na maioria das vezes, o que há de novo na educação de artistas não tem conexão direta com as preocupações dos artistas. A geração atual de artistas está sendo avaliada de acordo com planilhas cuidadosamente plotadas, rotuladas como metas de aprendizado, resultados, benchmarks, expectativas básicas, critérios de avaliação, conquistas cruciais e rubricas ${ }^{1}$.

É irônico, se essa não é uma palavra muito fraca, que nos mesmos anos em que a arte se moveu tão decisivamente do estúdio para o mundo, quando os artistas se tornaram tão engajados com etnia, gênero, lugar e identidade, quando a liberdade de expressão e pensamento passaram a contar tanto, também são os anos em que os artistas estudantes são julgados de acordo com páginas de critérios minuciosamente afinados, quantificados de maneira incremental e impecavelmente burocratizados.

O objetivo dos novos critérios não é limitar a expressão artística, mas permitir que os professores façam avaliações justas de seus alunos, ou reitores e administradores façam avaliações justificáveis de suas faculdades e departamentos para avaliarem criteriosamente a instituição como um todo. Os novos critérios são sobre equidade, responsabilidade e comparabilidade. Em teoria, isso não seria um problema, se fosse um processo executado em segundo plano sem afetar o que acontece no estúdio ou na sala de aula. Mas a linguagem das planilhas está se espalhando pelas salas de aula e, a partir daí, pela maneira como os artistas falam e pensam.

É fácil entender como esses novos critérios se espalharam. Faça uma pesquisa na Internet de "rubricas artísticas" e você encontrará imagens de centenas de planilhas. Uma pesquisa mais profunda de academias de arte, escolas de arte e departamentos de arte revelará que muitos publicaram suas planilhas online. Uma pesquisa no Google Livros sobre as palavras "avaliação" e "rubrica" mostra um aumento acentuado nesses termos nas mesmas três décadas: o problema está se acelerando².

Os critérios mensuráveis fazem parte da racionalização do ensino superior, iniciada no Reino Unido e na Austrália nos anos 1980, e agora se espalhou pela América do Norte, União Europeia e outros países. O centro da produção mundial de critérios quantificáveis para avaliação de estudantes é o Reino Unido, que codificou a avaliação quantificada no Research Assessment Exercise (raE) e seu sucessor, o Research Excellent Framework (rEf). Atualmente, o modelo do Reino Unido está em estudo para implementação nas universidades francesas e alemãs e exerce uma influência geral e generalizada na direção de maior complexidade e na quantificação sucessiva de critérios de desempenho de alunos e professores em todas as disciplinas. A influência do Reino Unido nos EUA é indireta e muitas vezes despercebida. Quando estou tentando afastar meus colegas da implementação de mais 
critérios, gosto de mencionar o índice h, inventado no Reino Unido, e seus sucessores, o índice i10 e o índice g. Essas são métricas que reduzem toda a produção de um acadêmico para um único número, que pode ser facilmente conectado às fórmulas que a universidade usa para ajudar a tomar decisões sobre a alocação de recursos. Essa desanimadora conquista administrativa tem sido objeto de muitos estudos no Reino Unido ${ }^{3}$. Na minha experiência, a maioria dos estudiosos da América do Norte não sabem disso, exceto talvez como um gráfico interessante em sua página do Google Scholar.

Quando tomei conhecimento desse problema, ele parecia abstrato e distante do meu campo. Ensino história e teoria da arte em uma escola de arte. Muitos dos meus alunos são artistas nos níveis de Bacharelado em Belas Artes (BfA) e Mestrado em Belas Artes (MfA). Converso com eles em seminários e aulas, visito seus estúdios e escrevo críticas de arte. Só encontro rubricas e outros critérios quantificados quando participo de comitês. Mas gradualmente, de forma tardia, percebi que a linguagem das planilhas está se tornando a linguagem da sala de aula, do estúdio e da crítica de arte e, portanto, também a linguagem que os alunos ouvem e falam. Vejo as palavras das planilhas nas declarações dos artistas que pedimos que nossos alunos escrevam e as ouço em suas conversas. A literatura administrativa quantificada está contribuindo para a produção artística da atual geração de estudantes: agora faz parte do mundo da arte, parte da história da arte.

A linguagem das planilhas está se tornando a linguagem dos estúdios de aula e da crítica de arte e, portanto, também a linguagem que os alunos ouvem e falam.

Na minha experiência, os professores que escrevem essas planilhas geralmente trabalham comparando o que outras instituições fizeram. $O$ trabalho lento no desenvolvimento de critérios quantificáveis ocorre nas conversas das reuniões do comitê. Palavras cujas histórias e significados alternativos podem não ser conhecidos são digitadas nas células das planilhas, onde são divididas em graus de sucesso ou fracasso e subdivididas em outras categorias. As planilhas são construídas em torno de um número relativamente pequeno de critérios generativos.

Por exemplo, espera-se que os estudantes de arte "sintetizem" a forma e a cor em suas obras de arte; para criar uma prática "unificada"; para "articular" a descrição de seus trabalhos; para definir "claramente" suas ideias principais; para ter uma boa ideia sobre sua "mensagem" ou "significado"; para desenvolver uma "posição", um "suporte" ou uma "perspectiva" em seu trabalho; para ser "reflexivo" sobre o que eles fazem; para desenvolver uma "linguagem visual" ou "competência visual"; para formular uma "agenda de pesquisa"; para ser capaz de falar sobre sua "investigação" ou o que eles pretendem "interrogar"; para estabelecer um "campo" ou "assunto" para o seu trabalho; para ser capaz de descrever sua "problemática"; e talvez, acima de tudo, criar para si uma "prática". 
Palavras como as que coloquei entre aspas parecem inócuas o suficiente, e podem sê-lo quando são usadas em conversas normais de estúdio. Mas se um departamento de arte dizer, em sua literatura oficial, que seus alunos aprenderão a "sintetizar" forma e cor, então o significado da palavra importa. $\mathrm{O}$ que deve contar como uma síntese inadequada? Existem tipos de síntese mais fortes ou mais fracos, aos quais podem ser atribuídos notas ou números? Que forma ou força de síntese contará como um cumprimento adequado do critério do departamento? E qual é o oposto da síntese?

Às vezes, é a forma e a cor que precisam ser sintetizadas; outras vezes, é forma e conteúdo, ou ideias e formas, ou apenas ideias. Os alunos da Escola de Arquitetura La Salle, na Universidade Ramon Llull, em Barcelona, foram solicitados a "aplicar um espírito de síntese de ideias e formas"4. $\mathrm{Na}$ União Europeia, as normas educacionais são monitoradas por uma série de acordos conhecidos como Processo de Bolonha. Entre seus documentos estão os "Descritores de Dublin", que pedem que os diplomas de pós-graduação sejam concedidos a estudantes capazes de "sintetizar ideias novas e complexas" ". Nos EUA, rubricas semelhantes podem ser encontradas na literatura do Associação Nacional de Escolas de Arte e Design (NaSad).

O manual do NASAD diz que uma das "competências essenciais" de um aluno é a "capacidade de analisar e sintetizar aspectos relevantes da interação humana em vários contextos (físico, cognitivo, cultural, social, político e econômico) ...". Em "Pintura", classificado como uma "competência essencial", há uma entrada que requer a "capacidade de sintetizar o uso do desenho, design bidimensional e cor". No nível do MFA, em "Requisitos Gerais: Arte", o manual lista várias habilidades, incluindo "conhecimento dos problemas e desenvolvimentos atuais", "habilidades de escrita e fala" e "competência profissional avançada" em alguma área do trabalho de estúdio; essa seção é apresentada com esta descrição: "Os elementos descritos [...] devem ser combinados e sintetizados em um indivíduo que exiba uma habilidade excepcional em arte ou design e uma estética pessoal bem desenvolvida".

Em cada um desses exemplos, a palavra "síntese" é essencial para o significado do critério. No entanto, sem uma definição de "síntese", cada um desses critérios recai no senso pessoal do professor sobre o desempenho do aluno - que é exatamente o tipo de confiança no julgamento subjetivo e incomparável que todo o sistema da avaliação quantificada pretende evitar.

Não é difícil ver como o conceito de síntese entrou nas rubricas da educação artística. No estúdio, os instrutores estão sempre atentos a sinais de que o trabalho do aluno seja unificado ou coerente. Geralmente, é bom quando um estudante de arte começa a fazer um trabalho que fala com uma única voz, que reúna uma variedade de materiais e técnicas ou mostre uma atitude coerente com a arte do passado. Pedimos aos nossos alunos que pensem em partes do trabalho que não se encaixam; sugerimos quais elementos podem funcionar bem juntos; damos conselhos sobre quais obras podem ir juntas em uma exposição. Dizemos que as partes, formas e ideias 
em seu trabalho devem se comunicar. Em resumo, esperamos que nossos alunos consigam reunir, a partir da gama desconcertante de possíveis influências e técnicas, uma prática coerente, mais ou menos unificada - o que costumava ser chamado de estilo.

A instituição onde ensino, a Escola do Instituto de Arte (SaiC), está colaborando com a Academia Central de Belas Artes de Pequim (Cafa) em um projeto chamado "Art Words", que analisa os critérios generativos como a síntese, em que se espera fornecer informações úteis sobre seus significados e histórias. A ideia é ajudar os administradores que constroem as planilhas, para que as palavras-chave possam ser usadas com mais precisão.

A síntese, por exemplo, tem uma história longa e complexa em filosofia. Conceitos como unidade e coerência atraíram a atenção de filósofos analíticos, críticos e até teólogos, e essa literatura pode ser muito útil para decidir exatamente o que "síntese" deve significar em qualquer caso.

O projeto "Art Words" está reunindo esse tipo de informação filosófica e etimológica, e também estamos analisando os usos das palavras na história da arte. Um resultado inesperado foi que os usos históricos das palavras frequentemente apontam para direções muito diferentes daquilo que as planilhas implicam.

A unidade da obra de arte é um antigo ideal, que pode ser atribuído a Aristóteles. Mas foi criticada no início do século XVIII, quando escritores como Novalis e Wilhelm von Schlegel defendiam e praticavam desunidades ${ }^{6}$. 0 fragmento era ideal para a arte muito antes da divisão da psique de Freud ou da desconstrução da intencionalidade no pós-estruturalismo. Embora as tentativas de síntese, unidade e coerência tenham continuado de várias maneiras, a crítica romântica do século XIX encerrou o período em que essas propriedades forneciam o modelo central da estrutura de uma obra de arte ${ }^{7}$.

Alguns artistas modernistas fizeram questão de não sintetizar seus precedentes históricos. A última pintura "retinal" de Marcel Duchamp (isto é, naturalista), Tum' (1918) tem elementos de perspectiva linear, teoria das cores, trompe l'oeil e arte comercial. Picasso, Hannah Höch, Kurt Schwitters e outros fizeram colagens intencionalmente desarmônicas. A ideia de que o estilo de um artista pode ser múltiplo já estava no ar na década de 1920. Francis Picabia, por exemplo, experimentou uma sucessão de estilos e mídias deliberadamente diferentes.

No século XXI, técnicas para produzir fragmentação, ruína e colagem fazem parte do kit de ferramentas de artistas contemporâneos. De fato, ensinamos estratégias de desunião no lugar das unidades aristotélicas, e nossos alunos praticam fazer trabalhos desunificados assim que tomam consciência da possibilidade. E, no entanto, nossas planilhas continuam exigindo síntese. Seria interessante acrescentar critérios de desunião romântica, modernista e pós-moderna. A síntese pode ser um critério para iniciantes e estudantes de arte de nível inferior ao BfA, e formas específicas de desarmonia e incoerência podem ser critérios no nível do MfA. 
Exceto para instituições pequenas e independentes, realmente não há como escapar da quantificação atual da educação artística. Infelizmente, é o período em que vivemos. O projeto SaiC / Cafa "Art Words" tem como objetivo fornecer material de referência que possa ajudar a encontrar palavras que possam complementar ou mesmo substituir conceitos como "síntese", para que nossa literatura administrativa possa representar melhor a arte que foi feita no último século ou mais ainda a arte que nossos alunos aspiram a fazer.

\footnotetext{
1 Nota das editoras: o termo "rubrica" refere-se a um guia de pontuação utilizado para avaliar a qualidade das respostas construídas dos alunos (composições escritas, apresentações orais ou projetos de ciência). Fonte: POPHAM, James. What's Wrong - and What's Right - with Rubrics. In: Educational Leadership. 55 (2): 72-75, 1997.

2 Ou tente "objetivo de aprendizado", "resultado do aprendizado", por exemplo, em xkcd.culturomics.org

3 Veja, por exemplo, a divertida conta de Roger Burrows, "Living with the H-Index? Assemblages in the Contemporary Academy," Sociological Review 60 no. 2 (May 2012), pp. 355-72

4 Citado em SHARE: Handbook for Artistic Research Education, editado por Mick Wilson e Schelte van Ruiten, 2014, p. 195; www. sharenetwork. eu/downloads

5 Consulte os descritores "Shared 'Dublin' descriptors for Short Cycle, First Cycle, Second Cycle and Third Cycle Awards", 18 de outubro de 2004, on-line em nvao.com

6 Ver, por exemplo, Elizabeth Harris, The Unfinished Manner: Ensaios sobre o fragmento no final do século XVIII (University of Virginia Press, 1994)

7 Pode-se dizer, por exemplo, que Jacques-Louis David sintetizou formas acadêmicas do século XVIII e o neoclassicismo recém-formulado; que Jean-Auguste Dominique Ingres sintetizou o "estilo trovador" medieval, a maneira de David e o neoclassicismo; ou que Édouard Manet sintetizou episódios históricos discretos na história da arte, de Ticiano e Velázquez ao realismo acadêmico. Mas o mesmo século viu o surgimento de pastiche e incongruência na escolha de estilos.
} 


\section{Referências}

BURROWS, Roger. Living with the H-Index? Assemblages in the Contemporary Academy. In: Sociological Review 60 no. 2 (May 2012), pp. 355-72.

CULTUROMICS. "Objetivo de aprendizado", "Resultado do aprendizado". Disponível em: xkcd.culturomics.org.

HARRIS, Elizabeth. The Unfinished Manner: Ensaios sobre o fragmento no final do século XVIII. University of Virginia Press, 1994.

NVAO. Shared 'Dublin' descriptors for Short Cycle, First Cycle, Second Cycle and Third Cycle Awards. 18 de outubro de 2004. Disponível em: www.nvao.com.

WILSON, Mick; RUITEN, Schelte van (ed.). SHARE: Handbook for Artistic Research Education. 2014, p. 195. Disponível em: www. sharenetwork.eu/downloads. 